\title{
EREBEA
}

Revista de Humanidades y Ciencias Sociales

Núm. 9 (2019), pp. 297-326

ISSN: 0214-0691

http://dx.doi.org/10.33776/erebea.v9i0.3792

\section{Las bases políticas de la Guerra de Sucesión en Andalucía: el Alcalde Mayor Rodrigo Caballero Illanes (I 7O I-I 740)}

Julio Martínez López

\section{RESUMEN}

Rodrigo Caballero Illanes se presenta, en palabras de Henry Kamen, como uno de los constructores de la supremacía borbónica en España. Este periodo en la ciudad de Cádiz fue fundamental en el devenir de la carrera profesional de Rodrigo Caballero coincidiendo con la Guerra de Sucesión Española. Caballero logró comprar una regiduría perpetua en el ayuntamiento de Cádiz, y más tarde, la alcaldía mayor de la ciudad. Durante la guerra Rodrigo Caballero levantó un regimiento de veteranos de 570 soldados siendo premiado por Felipe $\mathrm{V}$ con el grado de coronel de infantería. Igualmente, la averiguación de un intento de rapto de la familia real por parte de un grupo de colaboradores imperiales propició que Felipe V, en agradecimiento, lo nombrara Alcalde del Crimen de la Audiencia de Sevilla, e intermediara para la liberación de su hijo natural Rodrigo Caballero, el manco capturado por el ejército portugués.

Palabras Clave

Rodrigo Caballero Illanes; alcalde mayor de Cádiz; coronel de Infantería; alcalde del crimen Audiencia de Sevilla; rapto familia real; Guerra de Sucesión Española.

Fecha de recepción: 20 de noviembre de 2019 Fecha de aceptación: 5 de diciembre de 2019

\section{Abstract}

Rodrigo Caballero Illanes presents himself, in the words of Henry Kamen, as one of the builders of Bourbon supremacy in Spain. This period in the city of Cadiz was fundamental in the evolution of Rodrigo Caballero's professional career coinciding with the War of Spanish Succession. Caballero managed to buy a perpetual regiduría in the city council of Cádiz, and later, the mayor's office of the city. During the war Rodrigo Caballero raised a regiment of veterans of 570 soldiers being rewarded by Felipe $\mathrm{V}$ with the rank of infantry colonel. Likewise, the investigation of an attempted kidnapping of the royal family by a group of imperial collaborators led Philip V, in gratitude, to appoint him Mayor of the Crime of the Audience of Seville, and intermediary for the release of his natural son Rodrigo Caballero, the onearmed captured by the Portuguese army.

\section{KEYWORDS}

Rodrigo Caballero Illanes; Mayor of Cadiz; Colonel of Infantry; Mayor of the crime Audiencia de Sevilla; kidnapping royal family; War of Spanish Succession. 



\section{INTRODUCCIÓN}

El presente artículo de investigación tiene como objetivo analizar un periodo de suma importancia en el devenir del cursus honorum de Rodrigo Caballero Illanes. Una etapa en la que los eficientes servicios a la corona de Carlos II y Felipe $\mathrm{V}$ propiciaron el salto definitivo a las magistraturas, base de su larga y fructífera carrera en la administración real como intendente de ejército en el reinado de Felipe V.

Durante los 54 ańos al servicio de la corona espańola, Rodrigo Caballero se erigió como una pieza clave en la construcción del Estado Borbónico en España. Su esquela demuestra la extensa carrera profesional de nuestro protagonista: "el día 11, de este mes murió en esta Corte, de edad de 77 años, Don Rodrigo Cavallero y LLanes, Cavallero del Orden de Santiago, del Consejo de S.M. en el Supremo de la Guerra, en cuyo empleo, y otros, que exerció por espacio de 54 años, sirvió siempre con mucho zelo, aplicación, y desinterés" ". Esta hipótesis la confirma el hispanista Henry Kamen (1964: 368-395): "Intendentes como Patiño, su hermano el marqués de Castelar, Rodrigo Cavallero y Melchor de Macanaz deben ser recordados como los constructores de la supremacía borbónica en España”. Diez años después, el mismo autor concretó aún más su definición del valverdeño: "el más notable de ellos, por su largo tiempo a la Corona, fue Rodrigo Cavallero" (Kamen, 1974, p. 346).

Aunque existe una vasta documentación sobre Rodrigo Caballero Illanes por la propia naturaleza de los empleos que ostentó, es un personaje muy desconocido. Durante su largo cursus administrativo intervino en actuaciones de enorme calado para el devenir de la Estado Borbónico. Actuaciones que llevaron la impronta de su carácter preilustrado fruto de la influencia de los novatores valencianos. Algunos hitos que nos ayudarán a considerar el importante papel que jugó nuestro protagonista en el ramo de la hacienda y fiscalidad durante el reinado de Felipe V son: el diseńo en 1709 del conocido como Proyecto de la nueva Superintendencia General de Rentas de Rodrigo Caballero (Corona Marzol, 1985, p. 164), "el germen de las futuras intendencias" (Corona Marzol, 1987, p. 72); el novedoso modelo contributivo del Equivalente o Única General Contribución ${ }^{2}$, que más tarde se implantaría en todos los territorios de la Corona de Aragón

1 Gaceta de Madrid. 16 de agosto de 1740.

2 Archivo Municipal de Valencia. Sección Cartas Reales. 1709-1717. 
y en la Corona Castellana en tiempos de Fernando VI y la planificación de las reformas monetarias en las corona de Castilla y Aragón, con la consiguiente unificación monetaria en todo el Estado Borbónico en 1718: "En Castilla, el recién entronizado Felipe $\mathrm{V}$ - a través de las reformas de Rodrigo Caballero-está procediendo a la estabilización monetaria, abundando en las medidas iniciadas en 1686" (Vilar, 1974: 338-339).

Para proceder al desarrollo de la investigación y entender la relevancia del periodo gaditano en la evolución de su carrera profesional, es preciso realizar previamente una semblanza introductoria de Rodrigo Caballero y del contexto del que parte.

\section{Rodrigo Caballero Illanes}

Rodrigo Caballero Illanes nació en Valverde del Camino el 5 de agosto de 1663, en el seno de una familia hidalga de muy pocas rentas y condicionada por las duras circunstancias de la Guerra de la Restauración Portuguesa. Su infancia estuvo marcada por su futuro en la carrera eclesiástica y como fue costumbre en la época, los padres de Rodrigo Caballero Illanes ${ }^{3}$ vieron en la Iglesia la opción más segura para que sus hijos Diego Bernal Caballero y Rodrigo Illanes Caballero salieran de la pobreza predominante en el campo del Andévalo. Con diez años, Rodrigo se marchó de su ciudad natal hacia la capital hispalense para servir como fámulo ${ }^{4}$ al canónigo de la Colegiata de San Salvador don Diego de Espina y Aragón 5 . El anciano canónigo le procuró una formación académica avanzada que le permitió matricularse en el primer curso de cánones en el colegio mayor de Santa María de Jesús ${ }^{6}$, en la Universidad de Sevilla en 1681. Como manteísta se graduó como bachiller de cánones y leyes y se convirtió posteriormente en licenciado y abogado de los reales consejos ${ }^{7}$ en diciembre de 1684 .

Finalmente, antes de consagrarse al sacerdocio Rodrigo Caballero decidió dejar su vocación eclesiástica y comenzó su andadura profesional como corregidor y capitán a guerra de las villas de Chiclana y Conil de la Frontera (1686-1689), al servicio de su señor, el duque de Medina Sidonia Juan Claros Pérez de Guzmán.

3 Archivo Histórico Nacional, OM-Caballeros Santiago, Exp.1330. Concesión del Título de Caballero de la Orden de Santiago de Rodrigo Caballero Illanes. Rodrigo Caballero Illanes fue bautizado el cinco de agosto de 1663 en la Iglesia de Nuestra Señora del Reposo de la misma localidad, hijo de Juan Caballero Hidalgo y de María Domínguez de Illanes, naturales de Valverde del camino.

4 Criado doméstico de un convento u otra institución eclesiástica.

5 Archivo diocesano de Cádiz. Expediente matrimonial de don Rodrigo Caballero Yllanes y doña Agustina Josefa Enríquez de Guzmán. Provisato de obispado de Cádiz desde 24 de septiembre a 14 de noviembre de 1687.

6 Archivo Histórico Universitario de Sevilla. Pruebas de cursos en Canones, leies y Medicina desde 1678 hasta 1697. Libro 486.

7 AHN Osuna, Legajo 479, 65 y A.H.N. Universidades, L.404. Fol.236v. 
En 1686 con ocasión de la amenaza de una escuadra francesa en las costas de la Baja Andalucía, el valverdeño levantó cinco compañías de cien hombres en defensa de las posesiones ducales. Este periodo en la villa de Chiclana de la Frontera será fundamental en la vida de Rodrigo Caballero, ya que se casaría con Agustina Josefa Enríquez de Guzmán, rica y única heredera de un importante patrimonio procedente del legado de su abuelo, el capitán don Vicente Enríquez del Castillo ${ }^{8}$ y su padre, el capitán Sebastián Enríquez de Guzmán9. Asimismo con 12 años Agustina Josefa Enríquez añadiría a su cuantioso capital el mayorazgo de su tío, el presbítero y beneficiado de Mairena del Viso, don Francisco Enríquez de Guzmán ${ }^{10}$. Estas importantes rentas fueron hábilmente administradas por el valverdeño, que invirtió en diferentes varas que le proporcionarían la distinción y notoriedad suficientes para acceder a otros empleos de mayor relevancia.

La buena residencia como corregidor-capitán a guerra de Chiclana de la Frontera facilitó a Rodrigo Caballero recalar en la administración real cuando compró el oficio de alcalde mayor de la ciudad de Úbeda (1689-1690), asistiendo al corregidor el doctor Francisco Jiménez de Castilla ${ }^{11}$. Este corregimiento llevaba implícito el apresamiento y enjuiciamiento inmediato de la peligrosa banda de don Pedro de Messia. Con el éxito de este corregimiento Francisco Jiménez repitió experiencia con el valverdeño en 1694 en la ciudad de Jerez de la Frontera ${ }^{12}$.

La estrecha relación que mantenía con la casa ducal de Medina Sidonia permitió a Rodrigo Caballero estar al servicio del Bailío de Lora, frey don Alonso Pérez de Guzmán Marińón ${ }^{13}$, medio hermano del duque de Medina Sidonia. Para ello Rodrigo Caballero invirtió en la vara de gobernador, justicia mayor ${ }^{14}$, alcaide

8 AHPCA. Protocolos notariales. Chiclana de la Frontera. Protocolo no 57. Testamento Vicente Enríquez del Castillo.

9 AHPCA. Protocolos notariales. Cádiz. Protocolo no 3741.Escribano Juan Antonio Moreno. Testamento Sebastián Enríquez de Guzmán y Perea. El 13 de diciembre de 1682.

10 Archivo Histórico Provincial de Cádiz. Chiclana. Protocolo 59. Testamento de Don Francisco Enríquez de Guzmán y Perea. el 22 de enero de 1695.

11 AMVC. Hidalguía. Legajo 23. Acuerdo de recibimiento de los hijos de Rodrigo Caballero como hijosdalgos notorios de sangre y Papeles de Servicios de los quatro Capitanes de Ynfantería spañola don Sevastián, don Bicente, don Juan y don Rodrigo Cavallero hixos del Coronel de ynfantería Spańola don Rodrigo Cavallero Regidor Perpetuo de Cádiz del Consejo de Su Magestad, Alcalde de su Casa y Corte y Gobernador de la Sala del Crimen de la Chancillería de Valencia. 1707.”. Folios 28-82.

12 Archivo Histórico Provincial de Jerez de la Frontera (AHPJ) ańo 1694. Fol. 397.

13 Frey Don Alonso Pérez de Guzmán y Mariñón, el Bueno, era hijo natural del IX Duque de Medina Sidonia Gaspar Alonso Pérez de Guzmán, el Bueno y de su preferida Margarita Mariñón de Ibarra, natural de Madrid, hija de César de Mariñón, natural de Como (Milán) y de Beatriz de Ibarra y Mariaca, natural de Madrid. Alonso Pérez de Guzmán nació en Sanlúcar de Barrameda el 9 de marzo de 1637 y falleció en Madrid el 27 de agosto de 1708. Datos genealógicos extraídos de Céspedes Arechaga (1997).

14 Archivo Municipal de Lora del Río (AMLR) Actas capitulares. 5 de marzo de 1691. Reci- 
y castellano de la fortaleza de Lora del Río, con pleito de homenaje ${ }^{15}$. Este último hecho convirtió a Rodrigo Caballero en cavallero de un gran señor, ascendiendo en el cursus nobiliario de la pequeña nobleza castellana.

Tras un fugaz corregimiento en la villa de Huelva ${ }^{16}$ en 1695, un año después tuvo su primer contacto con el consistorio gaditano. Destinó una importante partida de dinero de la herencia de su mujer a la compra de la alcaldía mayor de la ciudad de Cádiz y sustituyó a José de Soto Guevara, asistiendo al complicado gobernador Francisco Fernández de Velasco Tovar $^{17}$ y más tarde a Francisco Miguel del Pueyo ${ }^{18}$.

Aunque la experiencia en este empleo duró solo cinco meses, Rodrigo Caballero pudo comprobar las grandes expectativas que se le abrían en este ayuntamiento. Conociendo los entresijos y la preocupante situación económica de algunos capitulares del regimiento de la ciudad, Rodrigo Caballero logró introducirse de lleno en el exclusivo regimiento gaditano al comprar en 1696 una regiduría perpetua al conde de Jimena de Líbar y vizconde de Almendralejo Esteban Chilton Fantoni ${ }^{19}$.

Este mismo año, ya como regidor perpetuo de Cádiz fue solicitado por el rey Carlos II a través del capitán general de Granada y de las costas de Andalucía y duque de Alburquerque, para que investigara sobre un turbio asunto en la ciudad fronteriza de Ayamonte. Caballero asumió la gobernación de la plaza de armas ${ }^{20}$ de esta localidad, sustituyendo al sospechoso maestre de campo Antonio López de Ogazón.

bimiento al licenciado y abogado de los reales consejos Rodrigo Caballero, como juez de residencia, gobernador y justicia mayor de la villa. El gobernador Caballero tuvo como teniente de gobernador y justicia mayor, al licenciado y abogado de los reales consejos Domingo Llorente de Carrillo.

15 AMLR. Actas capitulares.7 de enero de 1693.

16 AMH. Actas Capitulares. Legajo 12. Fol. 198. Cabildo del 17 de noviembre de 1695. Biblioteca Provincial de Huelva (BPH). Relación de servicios y méritos de don Rodrigo Caballero Yllanes. 1698.

17 Archivo Municipal de Cádiz (AMC). Actas capitulares, libro 52. 18 de febrero de 1696. Fols. $42 \mathrm{v}-46$.

18 AMC. Libro de Cabildo 52, 29 de mayo de 1696.

19 AMVC. Hidalguía. Legajo 23. Acuerdo de recibimiento de los hijos de Rodrigo Caballero como hijosdalgos notorios de sangre y Papeles de Servicios de los quatro Capitanes de Ynfantería spañola don Sevastián, don Bicente, don Juan y don Rodrigo Cavallero hixos del Coronel de ynfantería Spañola don Rodrigo Cavallero Regidor Perpetuo de Cádiz del Consejo de Su Magestad, Alcalde de su Casa y Corte y Gobernador de la Sala del Crimen de la Chancillería de Valencia. 1707". Fols. 28-82. Véase Fantoni Benedi (1985).

20 AMVC. Hidalguía. Legajo 23. Acuerdo de recibimiento de los hijos de Rodrigo Caballero como hijosdalgos notorios de sangre y "Papeles de Servicios de los quatro Capitanes de Ynfantería spañola don Sevastián, don Bicente, don Juan y don Rodrigo Cavallero hixos del Coronel de ynfantería Spañola don Rodrigo Cavallero Regidor Perpetuo de Cádiz del Consejo de Su Magestad, Alcalde de su Casa y Corte y Gobernador de la Sala del Crimen de la Chancillería de Valencia. 1707". Fols. 28-82. 
Con una hoja de méritos relevante y la intermediación del duque de Medina Sidonia, el licenciado y abogado de los reales consejos Rodrigo Caballero fue elegido diputado en cortes $^{21}$ (1697-1699) por el ayuntamiento gaditano para resolver varias demandas de la ciudad, entre ellas la cuestión del amurallamiento de la ciudad, principal problema de la población gaditana.

Durante esta estancia en la corte madrileña, Rodrigo Caballero contactó con el conde de Eril, próximo virrey del Perú y gobernador interino de Cádiz hasta su embarque hacia tierras americanas. El valverdeño aprovechó esta coyuntura para conseguir de Antonio Vicentelo Leca y Eril el empleo de alcalde mayor de la ciudad de Cádiz durante tres años, a cambio de un préstamo de 9000 pesos escudos de plata, que supuestamente le devolvería antes de partir al virreinato ${ }^{22}$.

\section{El TENIENTE GOBERNADOR Y ALCALDE MAYOR DE CÁdiZ} DON Rodrigo Caballero Illanes

El conde de Eril fue recibido con gran solemnidad en el Cabildo de la ciudad de Cádiz como gobernador ad interin el 12 de noviembre de 1699, mientras esperaba el apresto de la flota de los galeones que lo llevarían a tierra firme para tomar posesión de su cargo como virrey del reino del Perú. El mismo día, Antonio Vicentelo Luca y Eril nombró como su teniente de gobernador y alcalde mayor a "don Rodrigo Caballero Yllanes ${ }^{23}$ abogado de los Reales Consejos, Regidor Perpetuo de de esta Ciudad persona en quien concurren todas las partes y calidades que para el uso y exercicio de la vara" 24 .

Rodrigo Caballero había negociado con el conde de Eril las condiciones previas para su nombramiento el 26 de julio de 1699. Estas condiciones como hemos adelantado anteriormente se enmarcaban en un empréstito de 9000 pesos escudos de plata, y la vez, se comprometía el valverdeño a recaudar 1500 doblones entre los negociantes de la ciudad antes de su paso al virreinato del Perú25.

Rodrigo Caballero juró previamente su empleo en Madrid el 12 de agosto de 1699, ante algunos señores del consejo. Abonó los 2000 reales de vellón

21 AMC. Libro de Cabildo no 52. El 22 de abril de 1697.

22 Archivo Histórico Provincial de Cádiz (AHPC). Protocolo no 5157. Fol. 714.

23 Archivo Histórico Nacional, OM-Caballeros Santiago, Exp.1330. Concesión del Título de Caballero de la Orden de Santiago de Rodrigo Caballero Illanes. Rodrigo Caballero Illanes, hidalgo de pobre cuna, era natural de Valverde del Camino, fue bautizado el cinco de agosto de 1663 en la Iglesia de Nuestra Señora del Reposo de la misma localidad, hijo de Juan Caballero Hidalgo y de María Domínguez de Illanes, naturales de Valverde del camino.

24 Archivo Municipal de Cádiz (AMC), Libro del Cabildo no 54. 12 de noviembre de 1699. Fols. 321-325.

25 Para conseguir la cantidad comprometida se puso en contacto con diferentes banqueros extranjeros como Francisco Gironi y con comerciantes gaditanos de confianza, como Diego de Barrios y el regidor perpetuo Alonso de la Rosa. No obstante, sabemos por Francisco Gironi, que Diego de Barrios y Alonso de la Rosa declinaron el ofrecimiento de ayudar al conde de Eril. 
correspondientes a media annata, como era costumbre, con una duración de tres años ${ }^{26}$. Caballero había sido elegido por el conde de Eril "por las grandes experienzias que tiene y el credito y aprovazión con que a servido los empleos de Alcalde maior de Ubeda; Alcalde maior y corregidor de Jerez de la frontera y; alcalde maior también de la misma Ciudad de Cádiz; y el Gobierno de las Armas de Aiamonte y otros como a tenido de que consta en la relazión de servicios" ${ }^{27}$.

Según las ordenanzas reales, los alcaldes mayores debían ser naturales y vecinos de las ciudades donde iban a cumplir el empleo. Rodrigo Caballero no cumplía algunos requisitos exigidos para portar esta vara y así lo expresaba el propio conde de Eril: "y aunque el dicho don Rodrigo no lo es natural de dicha ciudad de Cádiz, ni tiene la vecindad en ella que la puede haver contraído, por razón del ofizio de Regidor y ser su mujer natural de dicha ciudad". Antonio Vicentelo Luca y Eril conocedor de las ordenanzas y trabas burocráticas "suplico se sirva de conzederme lizenzia en caso nezesario para poder nombrar por Theniente de Governador y Alcalde Maior de dicha Ciudad de Cádiz a el dicho don Rodrigo Cavallero". No obstante, el 3 de julio de 1699 el cabildo gaditano concedió a Rodrigo Caballero la licencia solicitada ${ }^{28}$ comenzando así su segunda etapa como alcalde mayor de la ciudad de Cádiz.

El día 1 de noviembre de 1700 falleció Carlos II, dejando la sucesión de todos los territorios del reino y dominios sin excepción a su sobrino nieto Felipe de Borbón, duque de Anjou, y nieto del Gran Rey francés Luis XIV y de la Infanta María Teresa, hija del rey Felipe IV de España.

Felipe $\mathrm{V}$ entró en la corte de Toledo el 18 de febrero de 1701 acompañado por su séquito de consejeros extranjeros, para ser coronado y ungido como rey de Espańa por el Cardenal Portocarrero. Inmediatamente, la corte, la nobleza y las ciudades elegidas convocaron la celebración de juramento de lealtad al nuevo monarca. Desde la corte madrileńa se mandaron urgentemente misivas a las ciudades para que eligieran a sus representantes para el juramento y pleito de homenaje como súbditos de Felipe $\mathrm{V}$ de Borbón, que se debía celebrar el 8 de mayo de 1701. El cabildo gaditano eligió a su alcalde mayor Rodrigo Caballero y al regidor Juan de Orta como representantes de la cuidad para jurarle lealtad y fidelidad como leales súbditos a su real persona con el simbólico besamanos.

En un ambiente de incertidumbre, el 9 de abril de 1701 Rodrigo Caballero firmó en Cádiz su primer testamento 29 "por salir de viaje en compañía con don Juan de Orta, Regidor perpetuo de Cádiz, por nombramiento del Cabildo y Regimiento para besar en su nombre la Real mano de S.M. el Rey don Felipe V”.

26 AMC. Libro del Cabildo no 54. 12 de noviembre de 1699. Fols. 321-325.

27 Archivo privado de Lucas de Siloniz Gil de Segredo. Legajo 29, no 1.

28 Ibidem

29 Archivo Histórico Provincial de Cádiz (AHPC). Protocolo, no 2816P. Fols. 19r-24v. Testamento de don Rodrigo Caballero. 9 de abril de 1701. 
El valverdeño comenta en ese documento que además de ir al besamanos tiene otros asuntos que no puede comunicar por ahora. Intuimos que el asunto secreto podría proceder del cardenal Portocarrero, en un intento por controlar los pasos de su gobernador, el ambiguo conde de Eril, pupilo del almirante de Castilla y claro opositor de la entrada de Felipe $V$ en el trono español. No sería de extrańar que Portocarrero también solicitara a Alcalde Mayor un informe exhaustivo periódico de todas las actuaciones y contactos del conde de Eril.

El 8 de mayo de 1701, el alcalde mayor Caballero realizó el juramento de lealtad a Felipe V, en San Jerónimo el Real de Madrid, mientras viajaba con el capitular Juan de Orta a la corte de Madrid. Rodrigo prometió obediencia, lealtad y fidelidad, igual que todos los títulos de Castilla, los prelados de la Iglesia y las ciudades más representativas, entre ellas Cádiz, que recientemente había conseguido de nuevo tener representación en las cortes.

\section{La guerra de Sucesión en la ciudad de Cádiz}

(23 DE AGOSTO DE I7OI-I I DE FEBRERO I705)

Muy posiblemente, los informes remitidos por el alcalde mayor Caballero al cardenal Portocarrero hablando sobre el conde de Eril, durante su viaje a la corte para el besamanos de Felipe V y más tarde a la vuelta a la ciudad de Cádiz, tuviera sus lógicas consecuencias. El Rey por mediación de Portocarrero y un consejo de asesores comenzó a colocar sus adeptos, fieles a la causa felipista en los cargos de relevancia de la Corona.

Las primeras medidas para comenzar la transformación militar de la ciudad de Cádiz fue el recibimiento el 23 de agosto de 1701 del general de batalla Scipion Brancaccio como nuevo gobernador ad interin de la ciudad, en sustitución del sospechoso conde de Eril. No sería de extrañar, que la lealtad y fidelidad de Rodrigo Caballero hacia el nuevo Rey fuera recompensada por el Cardenal Portocarrero, con la renovación de la vara de alcalde mayor de la ciudad de $\mathrm{Cádiz}^{30}$. El valverdeño realizó el juramento con la solemnidad acostumbrada en el cabildo, como teniente gobernador y alcalde mayor de la ciudad de Cádiz, en el ínterin de la gobernación de Scipion Brancaccio.

El mismo día se produjo el avistamiento de las velas de la armada enemiga por las costas andaluzas y la llegada del capitán general de la armada de Francia, defensor de las costas de España, el conde D’Estrés, que había llegado a la ciudad para comprobar en qué condiciones estaba la importante plaza de Cádiz. D’Estres fue recibido por el gobernador de Cádiz, el alcalde mayor Caballero y el maestre de campo, el conde de La Marquina Andrés de Alcázar y Zuñiga, representando al Cabildo ${ }^{31}$.

30 AMC. Libro del Cabildo no 57. Cabido del 23 de agosto de 1701.

31 AMC. Libro del Cabildo no 57. Cabildo del 23 de agosto de 1701. 
El alcalde mayor Caballero informó en el cabildo del 31 de agosto de 1701 sobre la presencia de una gran escuadra anglo-holandesa por los caños de Cádiz ${ }^{32}$. Enterada la población corrió el caos por toda la ciudad por temor al bombardeo indiscriminado de la escuadra enemiga. El vicario general y capitán general de la caballería de España del mar océano costas y ejército de Andalucía, Diego Dávila Mesía Felipez de Guzmán, marqués de Leganés, ordenó que en todos los barrios se repartieran tinas, cubos para agua y arena para apagar los fuegos y se hiciera acopio de aceite, tocino y leña para un posible sitio. Igualmente, éste concedió una cédula para la provisión de capitanes de las compañías vacas de milicia.

Existía un obstáculo difícil de superar, tanto los propios como los arbitrios de la ciudad estaban consumidos por haberse destinado a la fortificación y defensa de las murallas. En esta situación de urgente necesidad y sin liquidez alguna, Rodrigo Caballero propuso el nombramiento de cuatro diputados elegidos por el Cabildo para solicitar préstamos con un bajo interés a compañías de negocios y a particulares para financiar la defensa de la cuidad. El Cabildo lo aceptó acordando que en caso de que algún vecino principal se negara a colaborar de forma voluntaria se le prendiera. Los diputados elegidos fueron: el conde de la Marquina, el conde de Montecorto Juan Infante de Olivares y Cristóbal López de Morla y Villavicencio.

Con el enemigo a las puertas y solicitando la contribución de los vecinos más adinerados, se dio una situación extraña, que merece la pena comentar. El regidor perpetuo de la ciudad de Cádiz, Carlos Francisco Colarte, marqués del Pedroso denunció a Rodrigo Caballero ante el Cabildo el 28 de septiembre 1701 por el impago de las fianzas por el oficio de alcalde mayor en tiempos del conde de Eril y de Scipión Brancaccio ${ }^{33}$. El marqués del Pedroso solicitó sin perjuicio de la ciudad que se elevara este pleito a la justicia pertinente, mientras Carlos Francisco Colarte, por el contrario ofreció 1000 doblones que le había dejado su padre en un vínculo y mayorazgo. Este dinero iría destinado a la obra de la muralla, a la compra y mantenimiento de sogas y otros instrumentos para apagar los incendios. Este enfrentamiento abierto contra el alcalde mayor y el alarde de solidaridad hacia la vecindad gaditana tenía por detrás un trasfondo bastante oscuro que seguidamente explicaremos.

Durante la búsqueda del dinero por la llegada de la escuadra angloholandesa, los diputados elegidos fueron a la residencia del marqués del Pedroso, solicitando su contribución y préstamo a la causa de la defensa de la ciudad. La respuesta de Carlos Francisco Colarte fue negativa, argumentando que en ese momento no tenía liquidez, ni existía contrato alguno para tal concesión de dinero. La actuación del marqués del Pedroso, a los ojos de toda la ciudad fue bastante

32 AMC. Libro del Cabildo no 57. Cabildo del 31 de agosto de 1701.

33 AMC. Libro del Cabildo no 57. Cabildo del 28 de septiembre de 1701. 
negativa, por lo que se vio desplazado y se convirtió en objeto de las constantes críticas por parte del vecindario y sus compañeros de regimiento. Este acto de insolidaridad daba a entender que posiblemente el marqués del Pedroso fuera un austracista encubierto. En esta situación Carlos Francisco Colarte optó por el enfrentamiento directo con el precursor de la idea de la contribución, el alcalde mayor Caballero. Su reacción fue denunciar el impago de sus empleos durante los periodos como gobernador de la ciudad de Cádiz por parte del conde Eril y Scipion Brancaccio ${ }^{34}$.

Antes de que se complicara la situación y otros principales se acogieran a la misma aptitud de Colarte, Rodrigo Caballero optó por el camino de la negociación. Parece que las palabras del valverdeño fueron bien recibidas por Colarte, llegando a algún acuerdo. En noviembre se dejó constancia por escrito del compromiso contraído por el marqués del Pedroso de contribuir con una sustanciosa cantidad de dinero. Carlos Francisco Colarte argumentaba que tenía invertidos los 1000 doblones en la compra de trigo y hasta primavera no podría venderlo ${ }^{35}$. Como seña de buena voluntad éste aportó anticipadamente un tercio de los 1000 doblones comprometidos.

Gracias al archivo de los marqueses del Pedroso hemos advertido que el alcalde mayor Rodrigo Caballero aparece en esta fecha (1701) como acreedor de un préstamo de 1000 pesos escudos de plata ${ }^{36}$ al marqués del Pedroso Pedro Colarte. Seguramente, fueran destinados a la ayuda y defensa de la ciudad de Cádiz ${ }^{37}$. No sería de extrañar, que este empréstito estuviera dentro de las negociaciones entre el alcalde mayor y el marqués del Pedroso. Posiblemente, la reacción de Colarte fue producto de la falta de liquidez en ese momento, de ahí que Rodrigo Caballero se ofreciera prestándole 1.000 pesos, de forma que esta negativa a la contribución no fuera un punto de referencia para otros privilegiados, complicándose la financiación de la defensa de la ciudad.

El 23 de agosto de 1702 volvieron a saltar las alarmas, Rodrigo Caballero dio cuenta al Cabildo gaditano de una notificación enviada por el gobernador Scipion Brancaccio. Se había avistado por las costas de Andalucía, una gran armada angloholandesa compuesta por 196 velas $^{38}$, unos 60 navíos de guerra, 13 navíos de tres cubiertas, 9 cabos de bandera y, 10 galeotas de bombas, al mando del almirante James Butler, duque de Ormond. A una legua y media de distancia del castillo de San Sebastián la escuadra fondeó y las embarcaciones se extendieron como un cordón dirección a Sanlúcar de Barrameda, mientras que

34 AMC. Libro del Cabildo no 57. Cabildo del 28 de septiembre de 1701.

35 AMC. Libro del Cabildo no 57. Cabildo del 13 de diciembre de 1701.

36 Archivo privado de Lucas de Siloniz Gil de Segredo.

37 M. Bustos Rodríguez, Cádiz en el sistema atlántico. La cuidad, sus comerciantes y la actividad mercantil (1650-1830). Servicios de publicaciones de la universidad de Cádiz. Cádiz, 2005. p. 137.

38 AMC. Libro del Cabildo no 57. Cabildo del 23 de agosto de 1702. Fols. 218-219. 
otros tres navíos se colocaban en la boca de la bahía de Cádiz, bloqueando la entrada y salida de cualquier navío.

El 27 de agosto 1702, con el enemigo a pocas leguas y un futuro muy incierto para la ciudad, el cabildo decidió que el maestre de campo Andrés de Alcázar y Zúńiga, conde de La Marquina (Saavedra Zapater, 2000) ${ }^{39}$ y el procurador general de la ciudad salieran de ella en dirección a Madrid, llevándose los tesoros de la catedral y la custodia del Corpus Cristi, salvándola de los herejes ${ }^{40}$. El convoy dirección a la capital generó una huida en masa de la vecindad gaditana, agravando la situación que se estaba viviendo en la ciudad de la bahía y menguando de nuevo el grueso de la milicia gaditana. Con la guarnición mermada, la caída de la ciudad era cuestión de días. El duque de Brancaccio por mediación del Rey y el Consejo de Castilla publicó un bando para el alistamiento de todos los vecinos en los cuerpos de veteranos o en las milicias, "por hallarse muy corta la guarnición", proponiendo el levantamiento de un regimiento de 500 hombres $^{41}$.

Rodrigo Caballero consciente de que la conquista de Cádiz por parte de las tropas enemigas supondría la ruina total de la familia y la pérdida de todo lo conseguido hasta el momento, no tuvo otra opción que hacer otro esfuerzo económico de consideración. Como hombre principal de la ciudad y declinado abiertamente por el bando borbónico, sabía que sería uno de los primeros en ser objeto de las represalias austracistas. El teniente gobernador y alcalde mayor de la ciudad de Cádiz, el alcaide del castillo de Lora del Río Rodrigo Caballero Illanes acogiéndose al bando, levantó a su costa una compañía de 570 hombres, armándolos y municionándolos durante los 40 días de asedio. Al regimiento del valverdeño se le encomendó la defensa de los baluartes de los mártires capuchinos, de la puerta de la Caleta y el recinto sin amurallar hasta la iglesia mayor, y que actuara como retén para los socorros y asistencia de la isleta de San Sebastián ${ }^{42}$.

39 Sabemos que Andrés de Alcázar y Zúñiga, conde de La Marquina finalmente pasaría al bando austracista, siendo miembro de la corte del archiduque Carlos en la ciudad de Barcelona. Este fue perdonado por Felipe V el 22 de julio de 1716 con la obligación de vivir en Cádiz prohibiéndole el regreso a su corte.

40 AMC. Libro del Cabildo no 57. Cabildo del 27 de agosto de 1702.

41 Archivo Municipal de Valverde del Camino (AMVC). Hidalguía. Legajo 23. Acuerdo de recibimiento de los hijos de Rodrigo Caballero como hijosdalgos notorios de sangre y Papeles de Servicios de los quatro Capitanes de Ynfantería spañola don Sevastián, don Bicente, don Juan y don Rodrigo Cavallero hixos del Coronel de ynfantería Spañola don Rodrigo Cavallero Regidor Perpetuo de Cádiz del Consejo de Su Magestad, Alcalde de su Casa y Corte y Gobernador de la Sala del Crimen de la Chancillería de Valencia. 1707. Fols. 28-82.

$42 \mathrm{Ibidem}$. Estas acciones de guerra fueron certificadas y expedidas el 10 de diciembre de 1703 por Felipe Mazón y Blanco, veedor de la gente de guerra de la plaza de Cádiz y por Scipión Branccaccio, maestre General de campo, gobernador de lo político y Militar de la Ciudad de Cádiz. El maestre campo Antonio de Alexandro Barrientos concluía en su informe sobre los hijos del Rodrigo Caballero: "el valor correspondiente a sus obligaziones y asistieron con toda puntualidad a las demás funciones guardias y fajinas que se ofrecieron durante el sitio por que les considero dignos 
Este gesto arriesgado, de lealtad y fidelidad hacia Felipe $\mathrm{V}$ de Borbón, sería más tarde recompensado como veremos.

Los hijos mayores de Rodrigo Caballero Sebastián y Vicente Caballero Enríquez de Guzmán, de 13 y 11 años respectivamente, siguieron los pasos de su padre y se alistaron como soldados sencillos en la compañía y tercio de la armada del maestre de campo Antonio de Alexandro Barrientos, donde actuaron como ayudantes de las baterías que hacían fuego a los navíos y lanchas enemigas de Inglaterra y Holanda ${ }^{43}$.

Tras la fracasada incursión angloholandesa, pocos días después de la retirada de la escuadra enemiga de tierras gaditanas, concretamente, el 20 de noviembre de 1702, se leyó en el cabildo de la ciudad de Cádiz una carta real enviada por el marqués de Villadarias. La Reina María Luisa Gabriela de Saboya había despachado la epístola el 23 de octubre de 1702 por y ratificada por su secretario de cámara José Carrillo, por la cual, el Rey acogiéndose a las ordenanzas militares de Flandes (Borreguero Beltrán, 2001, p. 179) del 10 de abril de 1702, nombraba a Rodrigo Caballero Illanes coronel de infantería y le concedía 10 patente para levantar un regimiento de 10 compañías con sus capitanes ${ }^{44}$ "de haberle servido S.M. de onrarle con el empleo de Coronel de Ynfanería Española de los quinientos ombres que alisto y ocuparon los Valuartes de los Martires y Capuchinos Guarneciendo la muralla que ai de uno a otro en la ocasión que las armadas de Ynglaterra y Olanda pusieron cerco a esta Plaza”" ${ }^{45}$. El Rey ordenaba que todos los oficiales y soldados del ejército español lo reconocieran como tal coronel, obedeciendo las órdenes sin dilación, sin poner excusa alguna.

El marqués de Villadarias mandó que se asentara el regimiento y a Rodrigo Caballero en la plaza de Cádiz como coronel de infantería. Asimismo, se le concedía una patente en blanco para que alistase y nombrase a los capitanes reformados que creyera oportuno. El nombramiento recalcaba que "se le guardaran las preeminencias y libertades que le tocan por el empleo de coronel de infantería tomando razón de los oficios del sueldo que le toca por tal empleo" ${ }^{\text {46. }}$.

El propio cabildo recogía en sus libros los méritos de Rodrigo Caballero durante el sitio de la ciudad de Cádiz por la escuadra angloholandesa en 1702.

de las onrras que S.M. fuere servido hazerles". Sebastián y Vicente Caballero Enríquez de Guzmán fueron soldados sencillos en la compañía y tercio de la armada en Cádiz desde el 10 de junio de 1702 hasta el 9 de noviembre de 1702. Posteriormente pasaron a la plaza y frontera de Badajoz y más tarde fueron enviados con su tercio al reino de Galicia a las órdenes del capitán general Francisco Fernández de Córdoba.

43 Ibidem.

44 Para saber más sobre el levantamiento de regimientos en época borbónica F. Andújar Castillo, El sonido del dinero. Monarquía, ejército y venalidad en la España del siglo XVIII. Marcial Pons, Ediciones de Historia, Madrid, 2004.

45 AMC. Libro del Cabildo no 58. Cabildo del 20 de noviembre de 1702. Fols. 303-305.

46 Ibidem. 
El alcalde mayor levantó un regimiento de infantería de diez compañías de 50 hombres cada una, con gente de distinta clase: "hidalgos, reformados retirados a sus casas, escribanos, procuradores, navegantes, comerciantes de distintas rondas de rentas reales" ${ }^{37}$. Rodrigo Caballero pagó sus sueldos, gastos de armamento y munición, sin ser asistido por la real hacienda. En el escrito se deja constancia que los alistados, vecinos de Cádiz, se unieron con la única convicción de defender la plaza y sus casas, sin pedir sueldo alguno ${ }^{48}$. En el testamento del 18 de septiembre de 1716, Rodrigo Caballero menciona "que del tiempo que serví el empleo de Coronel de Ynfantería Española, se me están deviendo tres años de sueldo, con poca diferencia" ${ }^{\prime 4}$. Acogiéndonos a las ordenanzas militares de 1704 y sus modificaciones, el sueldo anual en estado de guerra correspondía a unos 1.200 escudos de vellón, un total de 3600 escudos de vellón era lo adeudado por la corona española ${ }^{50}$.

La guerra avanzaba, complicándose de manera extraordinaria el 12 de febrero de 1703. En Viena, el emperador Leopoldo I y su sucesor, el primogénito José de Habsburgo, cedieron los derechos al trono español al archiduque Carlos de Austria, quien se coronó en la capital austriaca el 12 septiembre de 1703 como Carlos III de España.

En esta coyuntura, según el memorial escrito por Rodrigo Caballero en 1707, el Rey y el Consejo le encargaron unas pesquisas secretas "en materias gravisimas y por la via reservada y por el Consejo se le dijeron muchas ordenes, a este fin obrando con especial zelo, advilidad y vijilancia y con la mayor safisfacion de S.M. y sentenzio dos de las espías a muerte a horca" ${ }^{21}$. Aunque no menciona el episodio y los personajes pues "y no los expressa, por politica necessaria, y porque V. Mag. los tiene preferentes" gracias a la investigación de María Luz González Mezquita en su obra Oposición y disidencia en la Guerra de Sucesión $n^{52}$ podemos poner en pie toda la escena.

47 Ibidem.

48 Ibidem.

49 Archivo del Reino de Valencia (ARV). Protocolo 7.300. Escribano Antonio Pastor (17151716). Folios 213-225. Testamento de don Rodrigo Caballero Yllanes. 18 de septiembre de 1716.

50 Archivo Municipal de Huelva (AMH). Actas capitulares año 1704. Ordenanzas militares de 1704 .

51 AMVC. Hidalguía. Legajo 23. Acuerdo de recibimiento de los hijos de Rodrigo Caballero como hijosdalgos notorios de sangre y Papeles de Servicios de los quatro Capitanes de Ynfantería spańola don Sevastián, don Bicente, don Juan y don Rodrigo Cavallero hixos del Coronel de ynfantería Spañola don Rodrigo Cavallero Regidor Perpetuo de Cádiz del Consejo de Su Magestad, Alcalde de su Casa y Corte y Gobernador de la Sala del Crimen de la Chancillería de Valencia. 1707.”. Fols. 28-82.

52 M. L. González Mezquita, Oposición y disidencia en la Guerra de Sucesión Española. Junta de Castilla y León. Consejería de cultura y turismo. 2007. 
La antipatía del almirante de Castilla hacia la causa borbónica era conocida entre los consejeros. Según recoge el marqués de San Felipe (Bel Bravo y Cañada Hornos, 1996), los aliados mandaron a un espía holandés que se hacía pasar por comerciante a la ciudad de Cádiz para analizar las defensas de las murallas, contabilizar las tropas destinadas en la ciudad y comprobar el ánimo de los habitantes de la ciudad con respecto a la causa felipista. El espía posteriormente se entrevistó con Juan Tomás Enríquez de Cabrera convenciéndole de que era muy probable la victoria austracista. Convencido el almirante de Castilla señaló en un mapa la situación de todas las fortificaciones y defensas que contaba la Corona española en la península. El almirante, como experto en los reinos de Andalucía, puesto que había sido el máximo administrador de esta tenencia, conocía todos los entresijos de estas tierras y el valor que tenían las fortificaciones y, sobre todo, la ciudad de Cádiz para una futura incursión por el valle del Guadalquivir hasta llegar a Sevilla ${ }^{53}$.

Los espías al servicio de la corona española pusieron en sobreaviso la traición del almirante de Castilla y el posible plan a llevar a cabo. La traición del Almirante de Castilla Juan Tomás Enríquez de Cabrera desestabilizó la corte castellana, un hombre con tanto poder e influencia podría generar una defección en masa de la aristocracia española. La preocupación de Luis XIV y de Felipe V no era vanal, de ahí que comenzara a moverse la maquinaria judicial y diplomática para la extradición del Almirante de Castilla exiliado en la corte portuguesa ${ }^{54}$. Para contrarrestar y justificar la traición del Almirante de Castilla, en septiembre de 1702 Felipe V ordenó al Consejo encausar a Juan Tomás Enríquez de Cabrera. El Consejo mandó realizar las testificaciones a sus más allegados, criados y parientes, con objeto de verificar y demostrar la traición del Almirante de Castilla e igualmente aprovecharían para conocer las posibles conjuras, destapar las redes de espías y sus colaboradores.

El 20 de abril de 1703 el visitador general del arzobispado don Pedro de Guzmán Maldonado comunicó a su pariente el coronel y Alcalde Mayor de la ciudad de Cádiz Rodrigo Caballero las noticias dadas por el don Pedro de Lanier, canónigo de la Santa Iglesia Catedral de Cádiz. Lanier había alquilado una habitación a un cirujano de nacionalidad genovesa y éste a su vez, invitó como huésped a Tomás José de Quintanilla, sumándose más tarde, Juan Díaz, antiguo criado del conde de La Marquina. Los tres marcharon hacia Portugal el 16 de marzo y volvieron el 17 de abril. Lanier informaba que la reunión y el viaje habían tomado un cariz muy sospechoso. La orden inmediata del alcalde mayor fue el apresamiento de ambos, que fue notificado al Rey y al Consejo. El Consejo ordenó a Rodrigo Caballero que se encargara como pesquisidor de la instrucción

53 Ibidem.

54 Ibidem .p. 282. 
y de las testificaciones de los sospechosos en la ciudad de Cádiz ${ }^{55}$. El valvedeño comenzó la instrucción con las diferentes declaraciones de los sospechosos y no escatimó en utilizar todo tipo de argucias para sacar la información requerida, incluso la aplicación de tormento. El alcalde mayor Caballero ordenó que se aplicara el tormento a Quintanilla hasta que le sacaran toda la verdad: "se le apercibió que si por no decir la verdad le saltare algún ojo o se le quebrare algún brazo o pierna o le sucediera otra fatalidad mayor sea por su quenta y que el dicho Sr. Alcalde Mayor solo desea aberiguar la verdad" ${ }^{\prime 56}$.

Parece que los tormentos tuvieron sus frutos esperados, Quintanilla y Díaz confesaron su delito y se retractaron. Ambos fueron contratados por el Almirante de Castilla por su juventud y necesidad económica para crear una red de espionaje. Los reos habían dando una valiosísima información sobre la cantidad de soldados, munición, regimientos, defensas, maestres de campo y un sinfín de datos sobre Cádiz, Rota, Sanlúcar y Sevilla para una futura incursión. Asimismo, dieron los nombres de algunos colaboradores. El 9 de mayo de 1703 fue enviada la instrucción del alcalde mayor al Consejo por mediación del Gobernador de Cádiz para el dictamen final. Días más tarde, concretamente el 9 de junio de 1703, el Consejo en pleno sentenció a la horca a los dos reos Quintanilla y Díaz y el escarmiento se produjo el 31 de agosto de 1703 en la plaza de la mayor de Cádiz. De esta instrucción no sólo escarmentaron los dos espías sino también un grupo numeroso de colaboradores austracistas de la ciudad de $\mathrm{Cádiz}^{57}$, concretamente 37 conjurados, que fueron enviados a prisión por un delito de traición. ${ }^{58}$ Sabemos que algunos ellos eran frailes victorios, que había un librero y algunos seglares que tenían poco afecto a Felipe $V$ y se inclinaban más hacia el Imperio ${ }^{59}$.

Gracias a las pesquisas de Rodrigo Caballero se advirtió que la red de espionaje y colaboradores era mucho más extensa y peligrosa de lo esperado, de ahí que se prosiguiera con las testificaciones en Cádiz por parte del alcalde mayor. Conocidos por los colaboradores y espías austracistas de los brutales métodos del valverde comenzaron a brotar multitud de datos e información sobre los secretos planes imperiales. El siguiente en testificar fue Enrique Francisco Vasein, Barón de Tambile quien declaró que el almirante y su facción estaban diseñando un

55 Ibidem. p.334.

56 Ibidem. p.334.

57 Ibidem. p.333.

58 AMVC. Hidalguía. Legajo 23. Acuerdo de recibimiento de los hijos de Rodrigo Caballero como hijosdalgos notorios de sangre y Papeles de Servicios de los quatro Capitanes de Ynfantería spañola don Sevastián, don Bicente, don Juan y don Rodrigo Cavallero hixos del Coronel de ynfantería Spañola don Rodrigo Cavallero Regidor Perpetuo de Cádiz del Consejo de Su Magestad, Alcalde de su Casa y Corte y Gobernador de la Sala del Crimen de la Chancillería de Valencia. 1707. Fols. 28-82.

59 González, op. cit. p. 2007.p.341. 
plan para secuestrar a Felipe V y su esposa en caso de que viajasen a Sevilla. Para ello, el Almirante contaba con una importante red de espías y colaboradores en la ciudad hispalense. Con el secuestro de los reyes, el Archiduque podría canjearlos por España, los Países Bajos y Borgoña. Concretaba que no escatimarían en “embenenar las aguas y volar los almacenes de pólvora” para conseguir el objetivo predeterminado, la captura de la familia Real ${ }^{60}$.

Tambile confirmó que el embajador extraordinario del archiduque, el Conde de Valdstein y el almirante tenían diferentes redes de espionajes en Cádiz, Madrid y otras partes de Espańa a la espera de actuar. El Barón de Tambile dio la noticia de que un tal Alonso el catalán tenía en su posesión más de diez mil armas destinadas a los confederados y que el almirante tenía en su residencia un arsenal que completaría el armamento de los austracistas. De las declaraciones se pudo sacar la valiosa información de algunos espías y colaboradores en Sevilla, como Gareau, el mencionado Alonso el catalán, el jesuita don Esteban y el clérigo don Sebastián. El 11 de junio de 1703 el marqués de Rivas escribía a Portocarrero informándole de los avances de las pesquisas del alcalde mayor de Cádiz gracias a los interrogatorios al barón de Tambile ${ }^{61}$.

Rodrigo Caballero pudo extraer de estas pesquisas más información relevante para el futuro de la guerra. Por lo visto, se estaba preparando una alianza entre los reinos moros norteafricanos e Inglaterra contra de la Corona Española. El Rey y el Consejo necesitaban información contrastada y de primera mano sobre la veracidad de estos datos. La orden de la pesquisa secreta llegó por mediación de Antonio Cristóbal de Ubilla, marqués de Rivas ${ }^{62}$ y despachada por el cardenal

60 Ibidem. p.342.

61 Ibidem. p. 346. Por orden del Duque de Brancaccio el pesquisidor Caballero continuó investigando sobre un asunto de un espía que fingía ser mudo y que traía algunos papeles de relevancia. Este había sido apresado por ser sospechoso de hacer espionaje (GONZÁLEZ MEZQUITA, 2007: 345) y ya preso fingió ser mudo, por lo que no pudo extraérsele ni una palabra. El 7 de julio de 1703 Rodrigo Caballero comenzó la pesquisa confirmando su identidad, era Pedro Díaz, un soldado de las galeras de Francia que había embarcado en Lisboa el 8 de mayo y salido sin licencia el 6 de julio de la galera. Sin poderle sacar ninguna información fue reconocido por un médico y un cirujano, y más tarde, por un exorcista franciscano, Fray Rosendo, que utilizando algunas reliquias y oraciones tampoco consiguió lo esperado. Pedro Díaz compartió calabozo con los sospechosos Quitanilla y Díaz y viendo como sentenciaban a muerte a los dos reos sufrió un "insulto apoplético", por lo que hubo que intervenirle de urgencia con sangrados y ventosas. Un individuo llamado Fernando Duarte reconoció al sospechoso sin ponerle nombre. Las sospechas de que se trataba de un espía austracista iban en aumento. No obstante, después de repetidos interrogatorios no se pudo extraer ningún tipo de información veraz. El 10 de junio de 1704 el alcalde mayor Caballero notificó al Consejo la imposibilidad de recabar ningún dato relevante puesto que era evidente su estado de locura.

62 AMVC. Hidalguía. Legajo 23. Acuerdo de recibimiento de los hijos de Rodrigo Caballero como hijosdalgos notorios de sangre y Papeles de Servicios de los quatro Capitanes de Ynfantería spañola don Sevastián, don Bicente, don Juan y don Rodrigo Cavallero hixos del Coronel de yn- 
Portocarrero. El cardenal daba órdenes, información y despachos para poder investigar el caso en profundidad. Después de una exhaustiva pesquisa, Rodrigo Caballero envío la información y los datos que solicitaban el consejo y el Rey. Aunque no sabemos qué información contenía la misiva, la consecuencia de su investigación fue el apresamiento de varios sospechosos, que fueron juzgados y enviados a presidio por alta traición. El asunto debió ser de consideración, ya que el 23 de mayo de 1703 el mismo Cardenal Portocarrero y el marqués de Rivas, secretario del despacho Universal felicitaron "a don Rodrigo por causas de inteligencia entre ingleses y moros" 63 .

Concluidas las pesquisas, Rodrigo Caballero retomó de nuevo el asunto de la guerra. Desde mayo de 1703, el reino vecino de Portugal era aliado del archiduque Carlos de Austria y el enfrentamiento entre los ejércitos español y portugués era cuestión de tiempo. Como coronel de infantería, Rodrigo Caballero debía ejecutar rápidamente las patentes otorgadas por el Rey: se había comprometido a levantar un regimiento compuesto de diez compañías de 50 soldados cada una. Para financiar el regimiento, el Rey le había concedido las patentes en blanco para que pudiera reclutar a los capitanes a su criterio y al precio que estimara conveniente. El 19 de octubre de 1703, el coronel de infantería Caballero rubricó una escritura de concierto y obligación ante el escribano Gerónimo Ruiz Arias, con siete capitanes para reclutar un regimiento de 500 hombres $^{64}$. Los capitanes que se ofrecieron para comandar las compañías fueron Martín de Béjar, Juan García de Mesa, Francisco Bernal Dávila, Francisco de Espinosa, José Ruiz de Rojas Arias, Martín Bersabe Cabeza de Vaca y Patricio Suarez de Monroy, todos vecinos de Cádiz. Estos habían sido los capitanes del regimiento del alcalde mayor Caballero que habían defendido con sus compañías los baluartes y murallas de Cádiz durante la fallida invasión de Cádiz, decidiendo seguir con el honor de llevar la bandera de sus compañías.

Rodrigo Caballero había depositado 3000 escudos de plata antigua como pago de su regimiento, obligando a los capitanes, que para poder mantener su graduación debían pagar mil pesos escudos de plata antigua. Estas cantidades irían destinadas a financiar el reclutamiento de "500 hombres desnudos" ${ }^{65}$. El coronel dividió el montante principal de 3000 pesos escudos de planta antigua entre seis capitanes, ya que Francisco García había fallecido antes de la firma de la escritura. Además, negoció con estos para fueran fiadores del ayudante Francisco de la Fuente, que traía de la corte de Madrid los despachos de los diferentes

fantería Spañola don Rodrigo Cavallero Regidor Perpetuo de Cádiz del Consejo de Su Magestad, Alcalde de su Casa y Corte y Gobernador de la Sala del Crimen de la Chancillería de Valencia. 1707. Fols. 28-82.

63 Ibidem.

64 AHPCA. Protocolo no 5581. Fols. 196-174.

65 Ibidem. 
capitanes. Sin tener dotes militares Rodrigo Caballero confió en la experiencia del alcantarino Pedro de Pontejos y Salmón nombrándolo sargento mayor del regimiento.

Martín Bersabé Cabeza de Vaca, sin solvencia económica, se veía obligado a hipotecar sus casas con licencia de su mujer, Teresa Carpintero, en la calle de La Murga. El aval estaba compuesto por tres viviendas que valían 77650 reales de vellón, alquiladas a Bartolomé Rodríguez Amador, que pagaba anualmente 200 ducados de vellón. Cada capitán iría entregando 500 pesos escudos de plata antigua para la recluta de 25 en 25 soldados, que se asentarían en el Castillo de Santa Catalina. Los soldados reclutados no debían estar casados, no podían ser negros, ni mulatos, ni extranjeros, ni menores de edad, ni quebrados, ni tullidos, ni marcados como fugitivos, y tuvieron como periodo máximo para la recluta hasta el 5 de marzo de 1704.

Como advertimos, fue muy difícil reclutar soldados en la ciudad de Cádiz, ya que los pocos hombres aptos que residían en la ciudad o habían sido enrolados en otros regimientos o habían huido del conflicto. Sin tener tiempo y comprometido con la Corona, el 21 de diciembre de 1703 Rodrigo Caballero firmó una escritura ${ }^{66}$ ante Lázaro López de Cuellar con José Jurado Valenzuela, vecino de Sevilla, residente en Cádiz y con Juan de Llera y Aranda, maestro herrador, obligándose ambos a la búsqueda y recluta de 500-600 hombres para el regimiento recién levantado del Coronel Caballero. Estos se obligaban al pago de seis pesos escudos de plata por cada hombre de 18 a 40 años reclutado. El coronel Caballero anticipó 600 escudos para la recluta que debía concluir antes del mes mayo de $1704^{67}$.

\section{Segundo inTento de INVASión de La CiUdAd de CÁdiz}

A comienzos de 1704 se planteaba una coalición militar de primer orden para la invasión definitiva de España por el ejército austracista. El archiduque Carlos de Austria llegaba a Lisboa a principios de marzo de 1704 en la armada del almirante Rooke para reunirse con su estado mayor, el príncipe de Darmstadt y el almirante de Castilla. Se levantó un poderoso ejército de 4000 ingleses, 2000 holandeses y 28000 portugueses, a la espera de la orden de invasión por las fronteras extremeñas ${ }^{68}$.

Para contrarrestar estas fuerzas, a primeros de febrero de 1704 el rey Felipe de Borbón firmó un decreto, por el que se comenzaban a organizar levas en las 17 provincias del reino para formar un ejército con 100 compañías $^{69}$. Se envío un gran contingente de fuerzas a la frontera extremeña con la intención de bloquear

66 AHPCA. Protocolo n²531.

67 AHPCA. Lázaro López de Cuéllar. Protocolo no 2531. folios 240-241

68 Albareda, op. cit. p. 2010, pp. 133-134.

69 Bustos, op. cit. p.1984, pp. 139-148. 
la incursión del ejército aliado, llevándose el Rey Felipe $\mathrm{V}$ su corte y cuartel general a Plasencia. La guerra se acentuó en las zonas fronterizas con el reino vecino y Galicia se convirtió un lugar destacado para la confrontación. El coronel Rodrigo Caballero y su mujer Agustina Josefa Enríquez de Guzmán, temerosos de la dirección contraria que podía tomar la guerra, decidieron poner de nuevo a sus hijos, Sebastián y Vicente de apenas 15 y 13 años, respectivamente, bajo su protección y seguridad en un lugar menos peligroso, pero dentro del ejército.

El coronel Caballero aprovechó las nuevas ordenanzas del ejército y sus contactos en la corte de Madrid para conseguir su propósito. Los soldados Sebastián y Vicente Caballero estaban asentados en el ejército de Galicia en una compañía de infantería, bajo las órdenes del maestre de campo Antonio Pacheco. Sebastián y Vicente Caballero estuvieron durante un año y 27 días en el frente gallego, concretamente, desde el 27 de mayo de 1703 hasta el 19 de mayo del año siguiente ${ }^{70}$.

Al valverdeño le había llegado la noticia que Sebastián de Olóriz iba a "levantar, vestir y armar de espada" a su costa 300 hombres $^{71}$ en siete compañías, incluida una comandancia en el tercio del maestre de campo Juan Fernández Pedroche. Este regimiento estaba asentado en la plaza de Cádiz y el coronel vio una oportunidad única para traerse a sus hijos a casa. Comenzó a realizar las gestiones pertinentes, comprando para ellos dos empleos de capitanes en el segundo batallón del coronel Sebastián de Olóriz. Previamente, Rodrigo debía contar con el permiso del capitán general de las costas de Andalucía, el marqués de Villadarias, con la licencia del capitán general de Galicia, el duque de Hijar y, cómo no, con la autorización final del Rey Felipe V.

Sus conversaciones y contactos en las altas esferas dieron los resultados esperados. El duque de Hijar accedió a conceder la licencia y la firmó en Tuy el 12 de junio de 1704. Menos de un mes después, el 20 de julio de 1704, el marqués de Villadarias asentó a Sebastián y Vicente Caballero Enríquez de Guzmán en el Puerto de Santa María como capitanes de infantería del segundo batallón del regimiento de Sebastián de Olóriz en la plaza de Cádiz, así como a José Olmedo, quien probablemente quien probablemente era hijo de su gran amigo el alcaide del castillo de Torre de Conil Antonio de Olmedo Ormaza.

$\mathrm{Al}$ no estar los pagos del ejército al corriente para que sus hijos "pudiesen servir con decencia”, el coronel tuvo que aportar gran cantidad de dinero de las arcas de

70 AMVC. Hidalguía. Legajo 23. Acuerdo de recibimiento de los hijos de Rodrigo Caballero como hijosdalgos notorios de sangre y Papeles de Servicios de los quatro Capitanes de Ynfantería spańola don Sevastián, don Bicente, don Juan y don Rodrigo Cavallero hixos del Coronel de ynfantería Spañola don Rodrigo Cavallero Regidor Perpetuo de Cádiz del Consejo de Su Magestad, Alcalde de su Casa y Corte y Gobernador de la Sala del Crimen de la Chancillería de Valencia. 1707. Fols. 28-82.

71 Ibidem. 
su mujer Agustina Josefa Enríquez de Guzmán. Según el testamento de Rodrigo Caballero, éste calculó los gastos totales de cada hijo durante sus periodos en el ejército, bajo el sustento y costas de su casa. Entraron en el ejército como soldados rasos en 1702, más tarde fueron capitanes vivos en el segundo cuerpo del tercio de Jaén, asentados en Cádiz y Badajoz y destinados posteriormente a los sitios de Badajoz, Serpa y Moura ${ }^{72}$. Como capitanes vivos y como señalaban las ordenanzas, debieron asumir los gastos de vestido, mantenimiento y armamento de sus compañías. Los gastos ocasionados por el capitán Sebastián Caballero ascendían a unos 2500 pesos escudos de plata, mientras el capitán Vicente Caballero necesitó 2000 pesos escudos de plata. No obstante, dejó bien claro en el testamento que él no disponía de dinero propio, señalando que los caudales dispuestos procedían exclusivamente de la herencia de Agustina Josefa Enríquez de Guzmán, su madre ${ }^{73}$.

A punto de declarar la guerra a las potencias aliadas, Felipe $V$ quiso saber sobre la situación de sus ejércitos y todo lo concerniente a la defensa de las principales ciudades. En el Cabildo del 18 de marzo de 1704 el conde de La Marquina, procurador mayor y diputado de guerra, leyó una carta real en que el monarca solicitaba un diputado para que le diera información exhaustiva de la situación en la que estaba la importante plaza de Cádiz, así como los regimientos de veteranos dispuestos en su defensa. El cabildo gaditano eligió al coronel Rodrigo Caballero como representante de la ciudad, encomendándole "que se pusiera a los pies de S.M." y que se dirigiera a la corte improvisada de Plasencia con una relación de demandas $^{74}$.

Una de las principales solicitudes fue la restitución a Cádiz de sus arbitrios en su antiguo uso, utilizando la mitad para pagar deudas contraídas durante la invasión de la armada angloholandesa que ascendían a 120000 pesos escudos de plata. Asimismo, utilizarían 60000 pesos escudos de plata para el levantamiento y sostenimiento de un regimiento de infantería de veteranos.

El coronel Rodrigo Caballero se desplazó a Plasencia a despachar con el Rey y el Consejo. No cabe duda de que el buen planteamiento del valverdeño y los méritos de la ciudad durante el asedio de la armada angloholandesa facilitaron la autorización del rey de algunas de las pretensiones del Cabildo gaditano. El Rey concedió la utilización de los arbitrios para pagar a los acreedores, mientras que se negó en rotundo al pago de los regimientos de las milicias, obligando a la ciudad al levantamiento de tres regimientos de veteranos. Uno ya había sido levantado

72 Archivo privado de Lucas de Siloniz Gil de Sagredo. Leg. 10, no 9.

73 AHN. Estado-Carlos III, Exp.437. Expediente de ingreso en la Orden Civil de Carlos III de Pedro Luis Gonzaga Caballero y Delfín Enríquez de Guzmán y Rodríguez, en 1790, folio 27. El testamento de Rodrigo Caballero otorgado en Sevilla 11 de septiembre de 1706 ante Juan Muñoz Naranjo.

74 AMC. Libro del Cabildo no 60. 18 de marzo de 1704. Folios 58-61. 
por el coronel Caballero, los otros dos deberían ser levantados a costa de la propia Ciudad $^{75}$.

Abierto el frente de Extremadura y localizado el grueso del ejército de Felipe $\mathrm{V}$ en la frontera con Portugal para bloquear la incursión de las tropas austracistas, los mandos aliados idearon y diseñaron otro plan para una nueva invasión de Cádiz con las informaciones obtenidas de la red de espías asentadas en Sevilla y Cádiz, como bien delataron los presos Quintanilla, Díaz y el barón de Tambile. El objetivo del almirante de Castilla era conquistar la ciudad estratégica de Cádiz, tomar posteriormente, Jerez de la Frontera y finalmente llegar a la ciudad de Sevilla, donde se instalaría la corte de Carlos III. Como se comprobó en 1702, la entrada de la armada por la bahía era prácticamente imposible, la guardia y custodia de las fortalezas de los Puntales y Matagorda se presentaban como unas defensas muy difíciles de neutralizar. El almirante de Castilla urdió un plan que podría inutilizar las defensas de las fortalezas, con la consiguiente vía libre para la toma de $\mathrm{Cádiz}^{76}$.

Enviaron de nuevo a las Costas de Cádiz ${ }^{77}$ una gran escuadra comandada por el almirante sir George Rooke y el príncipe Darmstadt. El 8 de mayo 1704 salió la armada del puerto de Lisboa con 32 navíos de guerra de línea, algunas fragatas y brulotes, además de los seis navíos del contra-almirante James Vishart, que se había adelantado días antes como avanzadilla. El ejército invasor estaba compuesto por 8000 soldados ingleses y 6000 holandeses, una cantidad muy superior a la reunida en 1702 .

El plan diseñado por el almirante de Castilla era simple pero muy efectivo, consistía en distraer la atención del verdadero objetivo, el castillo de San Sebastián, situado en la parte más exterior de la muralla. Mientras tanto, en el desconcierto de la batalla y la atención de las tropas gaditanas puesta en diferentes puntos de la ciudad, un grupo de colaboradores afines a la causa imperial abrirían las puertas del Castillo de San Sebastián. Acto seguido, una compañía inglesa debería hacerse con el control del castillo de San Sebastián y sus cañones, con esta defensa en poder de los ingleses, se podrían atacar posteriormente a la poderosa fortaleza de Santa Catalina y otras defensas de la muralla.

75 Bustos, op. cit. p.1984, pp. 139-148. Para reunir el dinero suficiente para financiar el levantamiento de los regimientos, ofreció la prórroga durante algunos ańos de los arrendamientos de la carne y del hacinamiento de la carnicería en 2000 y 3.000 pesos escudos, respectivamente. Al no ser suficiente, el Cabildo decidió el arrendamiento de las rentas de los propios más beneficiosos la "aduanilla y peso mayor" y el de los " 28 almacenes de Cádiz para el abasto de la ciudad", arrendado por Diego Lorion, de la nación francesa.

76 Castro, op. cit. p. 1854, p. 466.

77 Diario de la Expedición de las armadas inglesa y holandesa al mediterráneo, en las cuales se embarcó el Señor príncipe D. Jorge Landgrave de Hassia Darmstatt por orden de Su Magestad Catholica D. Carlos III. Lisboa, 1704. En la officina de Valentin de Acosta Deslandes. 
Para que se cumpliera el plan preestablecido, todo pasaba por la ayuda inestimable de los colaboradores pro-austriacos que serían los que abrieran las puertas del castillo de San Sebastián. Seguramente, el coronel Rodrigo Caballero gracias a las diferentes testificaciones durante la instrucción de Quintanilla, Díaz, Francisco Enrique Vasein, barón de Tambile y otros, supiera de posibles sospechosos o tuviera información secreta aportada por la inteligencia borbónica. Sea como fuere, las pesquisas del valverdeño dieron los frutos esperados y en el fragor de los cañonazos de los navíos ingleses y el consiguiente el desconcierto de la población gaditana, los conjurados se habían citado en la plaza de la ciudad para proceder con el plan diseñado por el almirante de Castilla. Sin embargo, la rápida actuación del coronel Rodrigo Caballero permitió el apresamiento momentos antes de la apertura de las puertas del castillo de San Sebastián: "el gobernador ${ }^{78}$ hizo abortar la conjuración tramada en la plaza para dar entrada a los ingleses, que se vieron en la precisión de retirarse". El nuevo fracaso de la armada angloholandesa, por hacerse con el control de la ciudad de Cádiz, precipitó un nuevo objetivo mucho más sencillo: la asequible de plaza de Gibraltar ${ }^{79}$.

No cabe duda que los servicios de Rodrigo Caballero acompañada de una incuestionable lealtad y fidelidad a la causa borbónica en tiempos tan convulsos fuera recompensada en 1705, con una plaza en la sala del crimen de la Audiencia de Sevilla ${ }^{80}$, y la intermediación del mismo monarca para salvar de una muerte segura a su hijo natural Rodrigo Caballero, el joven. Este inusual episodio es conveniente analizarlo, puesto que se confirma el reconocimiento y gran consideración de Felipe V hacia el "magnífico y amado" ${ }^{81}$ Rodrigo Caballero Illanes.

\section{La liberación del alférez Rodrigo Caballero, el Manco.}

78 C. Fernández Duro, Historia de la Armada. Instituto de Historia y Cultura Naval. Tomo 6. Pérdida de la plaza de Gibraltar. pp.49-65. Aunque se le atribuye al gobernador Scipion Brancaccio la resolución de la conjura, quien realmente realizó las pesquisas descubriendo la conjura fue el teniente gobernador, alcalde mayor y Coronel de Infantería don Rodrigo Caballero Yllanes.

79 Castro, op. cit. p. 1854, p. 466. Una plaza defensiva con una pequeña guarnición de 80 hombres y 30 caballos, bajo las órdenes de su gobernador Diego de Salinas. Las fuerzas de sir George Rooke necesitaban imperiosamente justificar su campańa naval y vieron en la plaza de Gibraltar, una fortaleza geoestratégica de relevancia, un segundo objetivo. El 4 de agosto de 1704 las fuerzas inglesas desembarcaron obligando al gobernador de la plaza a la capitulación. Tomada la fortaleza se izó la bandera inglesa y no la imperial como pretendía el príncipe Darmrstatd. El almirante inglés reclamó la posesión como territorio de la reina Ana de Inglaterra, quedando finalmente como presidio.

80 AMVC. Actas capitulares no 6. Año 1731, Memorial impreso de Don Rodrigo Caballero Yllanes, pidiendo a Su Majestad ser admitido en el Real y Supremo Consejo de Castilla. Relación de méritos de don Rodrigo Caballero, 1731.

81 Archivo Real de Valencia (ARV). Real Acuerdo del 14 de agosto de 1707. Francisco Comes. Fols. 69-72. 
Como hemos mencionado anteriormente, en el mes de febrero de 1704 la escuadra del almirante Rooke con el archiduque Carlos de Austria llegó a Lisboa. Venía rodeado de un gran ejército de alemanes, ingleses y holandeses bajo las órdenes de los generales Schomberg y Francois Nicolaas Fagel. A estos se le unió un enorme ejército portugués compuesto por 15.000 soldados regulares, además de 13.000 soldados milicianos, tal y como había acordado en su tratado de adhesión al bando austracista.

Para contrarrestar este potente ejército, el marqués de Villadarias y Francisco de Ronquillo Briceño agruparon un ejército de 30.000 soldados y algunos regimientos de caballería, a los que se les unirían las tropas mandadas por Luis XIV, bajo el mando de los generales Puysegur y el duque de Berwick. Ante esta situación, el 30 de abril de 1704 Felipe V, que se encontraba en Plasencia, declaró formalmente la guerra a la liga austracista y al pretendiente al trono, el archiduque Carlos.

Durante el verano de 1704, el grueso del ejército del príncipe de Tilly de Serclaes avanzaba por el margen izquierdo del Tajo con objeto de bloquear Arronches y las comunicaciones de las tropas enemigas. Sin embargo, el contraataque del ejército anglolusitano hizo recuperar las fortalezas de Montesanto, Ciudad Rodrigo y Fuenteguinaldo (Suárez Fernández, Corona Baratech y Armillas Vicente, 1984, pp. 241-242). El contundente envite de las fuerzas aliadas y la mala planificación estratégica de Tilly de Serclaes derivó en una gran pérdida de hombres y un estancamiento de la incursión. En el ejército Extremadura Viejo iba el regimiento de Gonzalo Baltasar de Carvajal y Valencia y, asentado en éste como alférez Rodrigo Caballero el joven, hijo natural del coronel Rodrigo Caballero y Manuela de Arévalo, nacido en Madrid en 1685.

El alférez Rodrigo Caballero fue hecho prisionero con otros oficiales y soldados de su regimiento, junto al teniente Gonzalo de Carvajal, muy posiblemente, pariente cercano del coronel del mismo nombre: Gonzalo de Carvajal. Durante la batalla, el alférez Rodrigo Caballero fue herido de gravedad en la mano izquierda, llegando a perderla. De ahí el posterior sobrenombre de "el manco". La inteligencia española había recabado la información del apresamiento de varios oficiales del ejército borbónico. Después de algunas pesquisas y contactos con el ejército portugués, se confirmó el apresamiento del alférez Rodrigo Caballero y del teniente Gonzalo de Carvajal en un presidio portugués ${ }^{82}$. Esta noticia fue trasladada a los mandos superiores para analizar la situación y concluir con una solución ventajosa para los capturados.

$\mathrm{Al}$ poco tiempo, llegó a los oídos del coronel Rodrigo Caballero la captura y reclusión de su hijo mayor. Sin tiempo que perder, el coronel se ofreció para conseguir algún trato de favor para la liberación de los oficiales. Para esto, el valverdeńo tuvo que contactar previamente con su general, el príncipe de Tilly

82 AHN. Estado. Legajo 260, no 13 entero. 
de Serclaes, con el marqués de Rivas, con el Coronel Gonzalo de Carvajal, con el Consejo de Castilla y con el mismísimo el rey de España para poder lograr la conmutación de la pena de muerte y la liberación de los oficiales capturados. Anteriormente, el coronel Gonzalo de Carvajal había solicitado urgentemente, el rescate o canje del teniente Gonzalo de Carvajal. El coronel Carvajal procuró información sobre la captura de Rodrigo Caballero el joven, pero no dio atisbos de interés en la liberación de su alférez, seguramente, pensando que el rescate de dos oficiales obstaculizaría la libertad del teniente Gonzalo de Carvajal.

Rodrigo Caballero el joven, había sido ascendido al empleo de alférez de la compañía recientemente y como oficial por uso y costumbre de la nobleza militar europea se le daba un tratamiento especial, por ser miembro del estado privilegiado. Eso le daba un tiempo crucial al coronel Rodrigo Caballero para unas posibles negociaciones para su rescate. El valverdeño logró mantener una línea directa de comunicación con Felipe $\mathrm{V}$, a través del marqués de Rivas, al que el coronel Rodrigo Caballero le había realizado algunos servicios de pesquisas, en busca y captura de espías austracistas. El 19 de septiembre de 1704, el príncipe de Serclaes, Alberto Octavio $T$ 'Serclaes de Tilly recibió la orden expresa del rey Felipe $V$ para la liberación a toda costa del alférez Rodrigo Caballero ${ }^{83}$. Inmediatamente, el príncipe de Tilly de Serclaes envió una carta a dom Diniz de Melo e Castro, Conde das Galveias, con objeto de conocer la situación del alférez Rodrigo Caballero y del teniente Gonzalo Carvajal. El príncipe Serclaes preguntaba

sobre el cange de don Rodrigo Cavallero, respecto de no haverlo executado todabia aunque an pasado muchos dias y ser la primera que le he escripto, y no saver como se admitira la proposizion que hize para conforme los terminos en que respondiere poder discurrir la forma de canjar a este teniente en cuya dependenzia no omitire ocasion ni diligenzia que nos lo fazilite ${ }^{84}$.

El interés de Felipe V presumía que había que hacer lo imposible para la liberación del prisionero.

El 10 de octubre de 1704, el rey Felipe V volvió a interesarse por la situación del alférez Rodrigo Caballero, escribiendo de nuevo al príncipe de Serclaes ${ }^{85}$. El 16 de octubre respondió Serclaes a Felipe V "que espera la respuesta de la que escrivio al Conde de las Galveas, tocante al rescate o cange de D. Rodrigo Cavallero para tratar del de el Theniente de D. Gonzalo Carbajal" ${ }^{66}$. Como vemos, parece extraño que un Rey, personalmente, se interesase de esa forma por un joven alférez, hijo natural de un coronel de infantería procedente de un linaje tan ínfimo. El 31 de

83 Ibidem.

84 Ibidem.

85 Ibidem.

86 Ibidem. 
octubre de 1704 llegó la gran noticia desde la plaza de Badajoz, el príncipe de Serclaes envió una carta al marqués de la Rivas informando

Señor mio: el Alférez Don Rodrigo Cavallero se halla ya en esta ciudad, haviendose logrado su cange con otro Alferez prisionero de las tropas de Portugal, en conformidad de lo que Vs. me previno de horden de Su Magestad en carta de 19 de septiembre próximo pasado, de que notizio a Vs. a fin de que se sirva de ponerlo en la Real ynteligenzia de su Magestad ${ }^{87}$.

Un año después, el 16 agosto de 1705 el alférez Rodrigo Caballero solicitó desde Badajoz al secretario de Guerra y Hacienda José Grimaldo Gutiérrez una compañía vacante, por la muerte de Juan de Verdugos en el regimiento del coronel Gonzalo de Carvajal ${ }^{88}$. Esta solicitud le fue denegada y Felipe V le concedió una capitanía de infantería en el regimiento de la costa de Granada, por haber pasado Juan de Albarracín a ser segundo teniente de una compañía de las Reales Guardias de Corps ${ }^{89}$. Sin duda alguna, tuvo mucho que ver en ello la intermediación y la compra del empleo de capitán en este regimiento por parte del coronel Rodrigo Caballero Illanes.

El valor y coraje en la guerra y, con ellos, las heridas y la pérdida de la mano durante las duras refriegas con el enemigo imperial, le valieron a Rodrigo Caballero, el manco, para dignificar a su padre y a su linaje, siendo premiado por su progenitor con un matrimonio muy ventajoso. Su cónyuge fue Inés Fernández de Bobadilla, hija del capitán de la flota de Nueva España, Manuel Fernández de Bobadilla, señor de la torre y solar de Bobadilla, caballero de la orden de Santiago o Calatrava ${ }^{90}$, y de Antonia Suárez de los Ríos ${ }^{91}$.

Tras estos servicios a la corona, en 1705 , por consulta de la cámara y con todos los votos a favor, el licenciado Rodrigo Caballero fue propuesto al Rey

87 Ibidem.

88 AHN. Estado. Legajo 269, Caja 2. Cartas

89 AMVC. Hidalguía. Legajo 23. Acuerdo de recibimiento de los hijos de Rodrigo Caballero como hijosdalgos notorios de sangre y Papeles de Servicios de los quatro Capitanes de Ynfantería spañola don Sevastián, don Bicente, don Juan y don Rodrigo Cavallero hixos del Coronel de ynfantería Spañola don Rodrigo Cavallero Regidor Perpetuo de Cádiz del Consejo de Su Magestad, Alcalde de su Casa y Corte y Gobernador de la Sala del Crimen de la Chancillería de Valencia. 1707. Fols. 28-82.

90 AHN. OM. Caballeros de Calatrava. Exp.889. Pruebas para la concesión del Título de Caballero de la Orden de Calatrava de Manuel Fernández de Bobadilla y de Otazu Armero y Liédana, natural de Sevilla. Aunque en los testamentos de Rodrigo Caballero y escritos de Florentina Caballero Enríquez de Guzmán lo nombran como Caballero de Santiago, podemos confirmar que fue Caballero de la Orden de Calatrava, no sabemos si logró también el hábito de Santiago.

91 Archivo del Reino de Galicia (ARG). Protocolo 4669/1014. Testamento de don Rodrigo Caballero Yllanes ante el escribano Andrés Zapata Taibo el 14 de diciembre de 1720. 
para acceder a una plaza en la sala del crimen de la Audiencia de Sevilla ${ }^{92}$. Ésta se configuraría como resorte para su posterior ascenso nombramiento como Alcalde Casa y Corte y Alcalde del Crimen de la Audiencia de Valencia en 1707.

En el Reino de Valencia Rodrigo Caballero desplegaría una serie de efectivas iniciativas fiscales y hacendísticas en la subdelegación de las rentas del tabaco que encumbrarían al valverdeño, siéndole concedido por Felipe $\mathrm{V}$ la merced de ingresar en la Orden de Santiago en 1709, y ser el primer intendente de ejército de la monarquía borbónica en 1711, junto con José Patińo. Fue el máximo responsable de las intendencias de ejército por espacio de 27 ańos, pasando por las intendencias del Reino de Valencia (1711-1717), del Principado de Cataluña (1718-1720), del Reino de Galicia (1721-1726), del Reino de Castilla-león (1727-1731), los Cuatro Reinos de Andalucía con la Asistencia de Sevilla (17321737), recalando finalmente en el prestigioso Consejo de la Guerra en 1738 hasta su fallecimiento en 1740 .

\section{Conclusión}

Rodrigo Caballero fue en palabras de Henry Kamen una figura clave en la construcción del Estado Borbónico. Tal vez la historiografía ha dejado de lado al valverdeño ya que no existe un estudio profundo sobre su figura. Pese a la vasta y significativa documentación existente acerca de Caballero, la tradición lo ha relegado a un papel secundario con el reconocimiento de hechos aislados o de escasa relevancia con relación a la construcción del Estado de Felipe V.

La existencia de escritos de ministros como José Patiño Rosales, José Carvajal Lancaster (1745), José Campillo Cossío ${ }^{93}$ o Melchor de Macanaz ${ }^{94}$ despertó el

92 AMVC. Actas capitulares no 6. Año 1731, Memorial impreso de Don Rodrigo Caballero Yllanes, pidiendo a Su Majestad ser admitido en el Real y Supremo Consejo de Castilla. Relación de méritos de don Rodrigo Caballero, 1731.

93 J. Campillo Cossio, Copia literal de un papel escrito por el señor [...] al Inquisidor de Logrońo sobre haberle formado proceso en punto de fe y acusado de que leía libros prohibidos y otras calumnias de sus émulos, con inserción de la carta que dirigió a dicho señor Inquisidor acompañando al citado papel, Guarnizo [1726], Madrid, 1789; Dictamen sobre cuál de los dos Capitanes Generales de Mar y Tierra deben tener más aplicación y estudio para las respectivas operaciones de sus encargos, 1739; Inspección de las seis Secretarías de Estado y calidades y circunstancias que deben concurrir en sus respectivos Secretarios [1739]; Lo que hay de más y de menos en España para que sea lo que debe ser y no lo que es. [1742]; Espańa despierta, c. 1743.

94 M. R. Macanaz, Disertación histórica que sirve de explicación a algunos lugares obscuros que se encuentran en la historia, cartas, alegaciones y apología que ha dado a luz el Cardenal Alberoni, 170; Explicación jurídica e histórica de la consulta que hizo el Real Consejo de Castilla a el Rey Nuestro Señor sobre lo que S. M. le sirvió preguntarle, y se expresa en esta obra con los motivos que dieron causa para la real pregunta y respuesta, y defensa legal de una de las principales partes que componen el todo de la soberanía de Su Magestad, 1709. Regalías de los Señores Reyes de Aragón. Discurso jurídico, histórico, político, 1711. Monumento de fidelidad y gratitud, erigido en las fiestas con que celebró el dichoso Nacimiento del Serenísimo Infante de España, Don Felipe, 
interés y la curiosidad de algunos autores que realizaron estudios biográficos que realzaban la figura de estos personajes, pero no la del valverdeño. Así, el académico de la historia Antonio Rodríguez Villa ${ }^{95}$ estudió sobre el marqués de la Ensenada, Campillo y Patińo. A este último también le han dedicado investigaciones Antonio Valladares Sotomayor (1790), Pulido Bueno (1998) y Pérez Fernández-Turégano (2004). Henry Kamen (1965) y Martín Gaite (1969 y 1971$)^{96}$ se dedicaron a las reformas políticas de Melchor de Macanaz, mientras que Ozanam (1975) investigó la política diplomática de José de Carvajal.

Este desconocimiento sobre Rodrigo Caballero se acentúa aún más cuando otros historiadores han adjudicado muchos hitos de clara titularidad del valverdeño a otros ministros, como las erróneas autorías que adjudica el historiador catalán Joan Mercader Riba a José Patiño sobre el acertado cálculo en el Catastro del Principado de Cataluña (Mercader Riba, 1966a) o la llamativa organización de la expedición militar que conquistó el Reino de Sicilia (Mercader Riba, 1966) en 1718, también adjudicada al mismo ministro.

El objetivo de este primer artículo de investigación sobre el valverdeño es dar a conocer algunos episodios de la larga y fructífera carrera profesional de uno de los constructores de la supremacía borbónica en España: Rodrigo Caballero Illanes.

\section{Bibliografía}

Bel Bravo, M.a A. y Cañada Hornos, M. J. (1996). Repercusiones sociales de la Guerra de Sucesión en Andalucía: El caso de Torredonjimeno. Boletín del Instituto de Estudios Giennenses, 162(2), 1031-1072.

Borreguero Beltrán, C. (2001). Del tercio al Regimiento en Real. Valencia: Sociedad Económica de amigos del País.

Carvajal Lancaster, J. (1745). Testamento político reducido a una idea de un gobierno católico, político, militar y económico, como conviene para la resurrección y conservación de España. En Almacén de Frutos Literarios, I, Madrid, 1818.

Céspedes Arechaga V. (1997). Pruebas de ingreso en la Orden de San Juan, que se conservan en el Archivo del Infante don Gabriel de Borbón, siglos xvi y xvii.

Don Melchor de Macanaz, Zaragoza, 1712; Proposición que el Fiscal General hace al Consejo, en nombre de S. M., por el bien público del Estado, sobre que se enseñen y lean en las Universidades las leyes del Reino, 1713; Representación que Don Melchor de Macanaz, Fiscal del Consejo Real de Castilla, hizo a S. M. sobre el estado eclesiástico, secular y regular de Espańa, 1713; Pedimento Fiscal sobre abusos de la Dataría o Pedimento Fiscal de los 55 puntos o artículos, 1713.

95 A. Rodríguez Villa, Don Cenón de Somodevilla, Marqués de la Ensenada: ensayo biográfico formado con documentos en su mayor parte originales, inéditos y desconocidos. 1878; Patiño y Campillo: reseña histórico-biográfica de estos dos ministros de Felipe V, formada con documentos y papeles inéditos y desconocidos en su mayor parte. 1882.

96 Véase T. Egido (1981 y 1984). 
Hidalguía. La revista de Genealogía, Nobleza y Armas, XLV(261), marzo-abril, 208-209.

Corona Marzol, C. (1985). La intendencia de Valencia en el siglo XVIII (17001770) (tesis doctoral inédita). Zaragoza: Universidad de Zaragoza.

Corona Marzol, C. (1987). Un centro de experimentación castellana en Valencia: La Superintendencia General de Rentas Reales (1707-1713). Estudis. Revista de historia moderna, 13, 171-200.

Benedi, R. (1985). Los Fantoni: Regidores Perpetuos de Cádiz (1596-1835). Revista Hidalguía, núm. extraordinario, 231-250.

Egido, T. (1981): La proyectada reforma inquisitorial de Macanaz en su contexto político. En VV. AA., Mayáns y la Ilustración. Simposio Internacional en el Bicentenario de la muerte de Gregorio Mayáns (pp. 17-28), t. I. Valencia: editorial

Egido, T. (1984). Las reformas fracasadas. El significado de Macanaz. En B. Escandell Bonet y J. Pérez Villanueva, Historia de la Inquisición en España y América (pp. 1234-1247), tomo I. Madrid: editorial.

Kamen, H. (1964). El establecimiento de los Intendentes en la administración Española. Hispania: Revista española de historia, 95, 368-395.

Kamen, H. (1965). Melchor de Macanaz and the foundation of Bourbon power in Spain. The English Historical Review, 80, 699-716.

Kamen, H. (1974). La guerra de sucesión en España 1700-1715. Barcelona: Ediciones Grijalbo.

Martín Gaite, C. (1969). El proceso de Macanaz: historia de un empapelamiento. Editorial Moneda y Crédito

Martín Gaite, C. (1971). En el Centenario de Don Melchor de Macanaz (16701760). Revista de Occidente, XXXII(94), 49-60.

Mercader Riba, J. (1966): Un organismo-piloto en la monarquía de Felipe V: La Superintendencia de Cataluña. Hispania: Revista española de historia, 104, 526-578.

Ozanam, D. (1975). La diplomacia de Fernando VI. Correspondencia reservada entre Don José de Carvajal y el Duque de Huéscar, 1746-1749. Madrid: Consejo Superior de Investigaciones Científicas.

Pérez Fernández-Turégano, C. (2004). José Patiño y las reformas de la Administración en el reinado de Felipe V. Madrid: Instituto de Historia y Cultura Naval.

Pulido Bueno, I. (1998). José Patiño. El inicio del gobierno ilustrado en España. Huelva: Artes Gráficas Andaluzas. 
Saavedra Zapater, J. C. (2000). Entre el castigo y el perdón. Felipe V y los austracistas de la Corona de Castilla, 1706-1715. Espacio, Tiempo y Forma, Serie IV, Historia Moderna, t. 13, pp. 469-503.

Suárez Fernández, L., Corona Baratech, C. E. y Armillas Vicente, J. A. (1984). Historia general de España y América. Madrid: Ediciones Rialp.

Valladares Sotomayor, A. (1790). Fragmentos históricos de la vida del excelentísimo señor don Josef Patińo, secretario que fue de Estado, Hacienda, Marina e Indias, en el reinado del señor Don Felipe V. Semanario Erudito de Valladares, XVIII, 72-118.

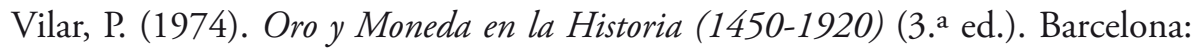
Editorial Ariel. 